\title{
Research on the parameters of light emitting advertising media
}

\author{
Marcin Chrzanowicz ${ }^{1, *}$, and Piotr Tomczuk ${ }^{2}$ \\ ${ }^{1}$ Warsaw University of Technology, Faculty of Electrical Engineering, Warsaw, Poland \\ ${ }^{2}$ Warsaw University of Technology, Faculty of Transport, Warsaw, Poland
}

\begin{abstract}
This article presents preliminary test procedures for measuring the light performance of advertising media related to the way that the light beam affects the driver. A basic distribution of advertising in terms of light emission and estimated luminance levels that can cause blinding. Finally, the results of the diminishing of the luminance of the surface; examples of luminous ad types and identifies their impact on visibility in terms of the possibility of blinding that results in the deterioration of road safety (especially at night ).
\end{abstract}

\section{Introduction}

The problem of the assessment of the impact of advertising media located in the vicinity of roads on motorists can be considered in a number of ways. The factors which can draw the driver's attention to the advertising medium have many causes. You can classify them as: aspects of the content, location, geometry, psychological and lighting. Each of the foregoing factors may significantly affect the conditions and hinder the driver's vision.

The study of the effects of advertising media located in the vicinity of roads within the driver's view [1,2] testify to the existence of a number of research problems related to lighting performance. The research carried in Poland [3,4] and a number of other countries [5-7] shows the need for the use of lighting parameters such as luminance and contrast $[8,9]$ in the assessment of the impact of advertising on drivers. The lighting parameters that can be analysed in the context of advertising light are the advertising's luminance area, the luminance contrast between the advertisement area and the background, the distribution of the colours of the light, the illuminance on the plane of the driver's eyes produced by the advertising area and how the light is emitted (continuous or variable, directional or diffuse). In addition, you can analyse geometric parameters such as the angular size of the advert and the location of the field of vision. Advertising media is often characterized by variable luminance on its surface; this is particularly evident in the case of advertising with an external light source. The maximum value is obtained by examining the surface of the advertising perpendicular to the geometric axis of advertising media. However, with the increase in viewing angle value decrease is therefore an important issue is to determine the actual levels of luminance advertisements [2,7] of the lines of sight of the driver.

The luminance contrast with the background of the ad space is the ratio of the luminance difference between the observed object and the luminance of the background. Large values of luminance contrast can blind drivers [12]. The possibility of misleading the driver is a

* Corresponding author: marcin@zkue.ime.pw.edu.pl 
dangerous aspect of road safety. In the case of advertising light there is such a risk as a result of similar lighting values and emission colour from the advertising carrier and the indicator light. In order to determine these parameters and neutralize the threat it is necessary to study advertising in terms of luminance and chromaticity and comparison with the colours of regular traffic light.

Driver distraction can be caused by the excessive brightness of advertising media, uneven distribution of luminance, high contrast and high luminance variation in time (variable message advertising).

\section{Division of advertising in terms of the direction of the emission of the light beam}

The introduction of the split of advertising is necessary because of the different visual impressions caused by different light distribution. The advertisement area can emit a light beam in a perfectly distributed (Lambert reflection) and mixed way. The most disturbing LED directional advertising light distributions are shown in Figure 1.

\section{Screen group A (LED)}

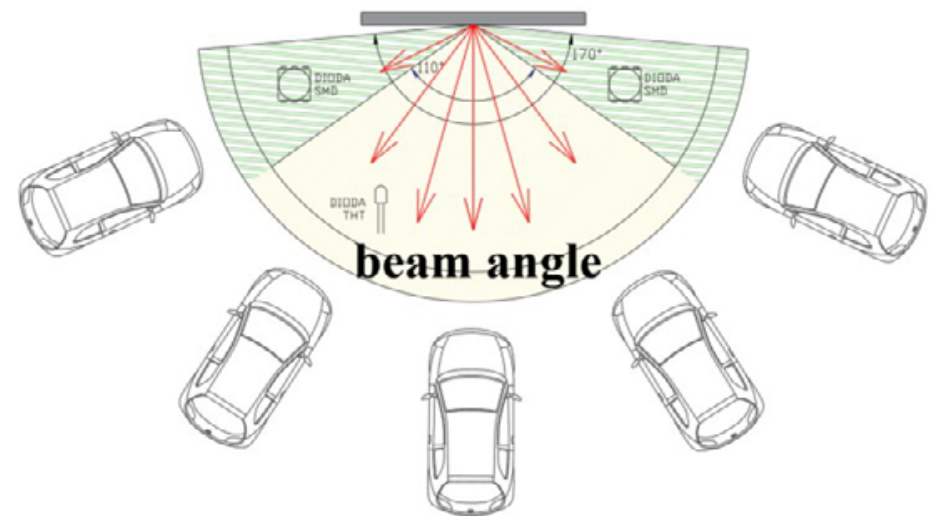

Fig. 1. Character of the emission light emitted from LED advertising.

The presented character of the distribution means that the impact of the media is highly dependent on the angle of observation, and thus at certain geometrical settings the advertising will increase the impact of distractions and at others it does not interfere. Maximum glare occurs in a direction perpendicular to the carrier. As a result of the study, the field analyses of the advertising suggested the division shown in Figure 2.

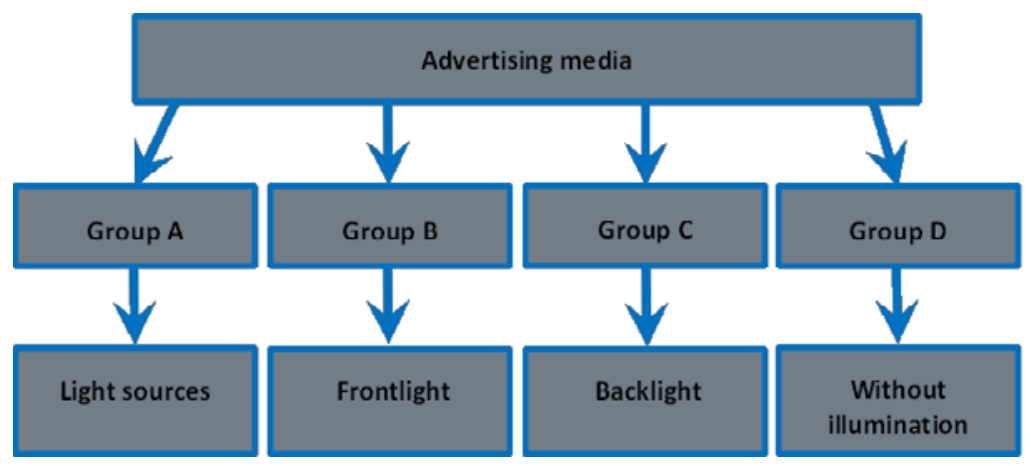

Fig. 2. The division of advertising media in terms of light emission. 
Group A included media whose surface is also a source of light where the emission beam is highly directional. Group B and $\mathrm{C}$ are carrier surfaces which are illuminated by additional fittings (from the front and the rear of the vehicle respectively), and thus their reflection characteristics is similar to Lambert reflection light scattering (ideal dispersion). Group D is the media that do not emit light. It should be noted that the division is presented as a preliminary concept which will be expanded with of indirect and mixed variants.

\section{Initial test procedures with examples of test results of lighting parameters}

The carriers of variable content in which the surface luminance changes in a dynamic way are a separate issue. The distribution of light intensity affecting the eyes of a driver in the vicinity of the advertisement is presented in Figure 3.

Registering presented the course requires a light meter with very fast sampling (approximately $25 \mathrm{~Hz}$ ). A large gradient change of lighting parameters can also distract, and the scope of changes force the team investigating to find the worst-case (to determine the maximum gradient variations in lighting on the driver's eyes).

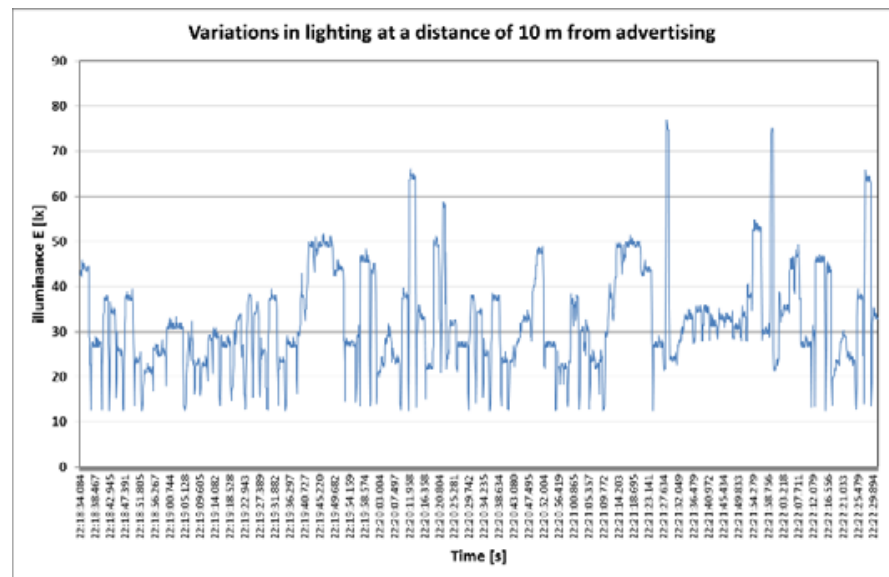

Fig. 3. Distribution of advertising media due to the emission of light.

Considering the luminance distribution of advertising media it is necessary to develop a measurement procedure which explicitly and repeatedly verifies the worst case emission of the light beam. The first prerequisite is the measurement of the direction with the largest emission of light (in the driver's field of vision). It is usually the direction perpendicular to the support (depending on the photometric solid). The second condition is to define the maximum size of the measuring field and a minimum amount of measurement areas. In order to search for the optimal values the measure of the luminance of the surface of advertising as a function of the size of the measuring field were analysed. They were chosen from the group ad A that has a surface light source. The purpose of the measurement was to find the maximum value. Taken measurement of the luminance distribution meter matrix CCD whole carrier surface with a resolution of approximately 320 thousand points, treating it as a study model (Fig. 6). Then analysed variables size measurement fields and their impact on the value of the maximum luminance (Fig. 4 and 5). The measurement data are summarized in Table 1 , together with an analysis of the error with respect to the calibration measurement (meter matrix). 


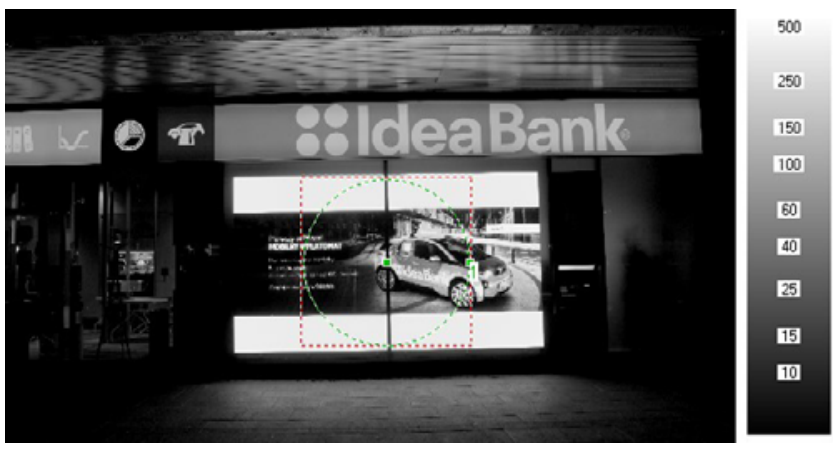

Fig. 4. The search for value Lmax [cd / m2] in one field of measurement (126000 pix).
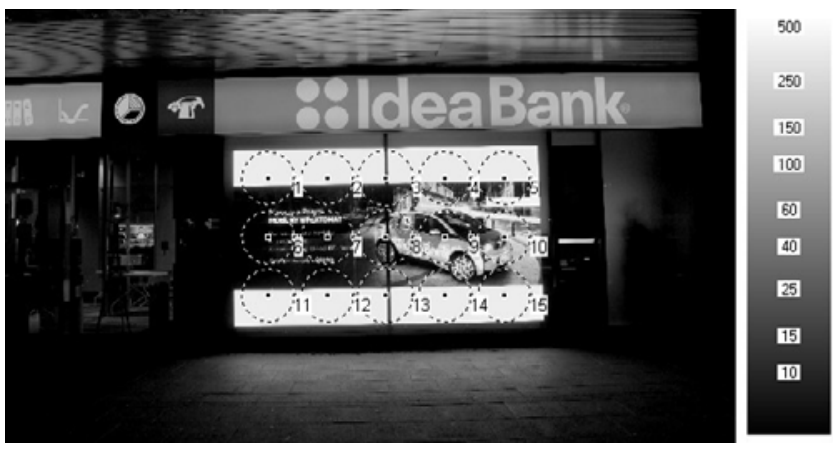

Fig. 5. The search for value Lmax [cd / m2] for 15 measurement fields.

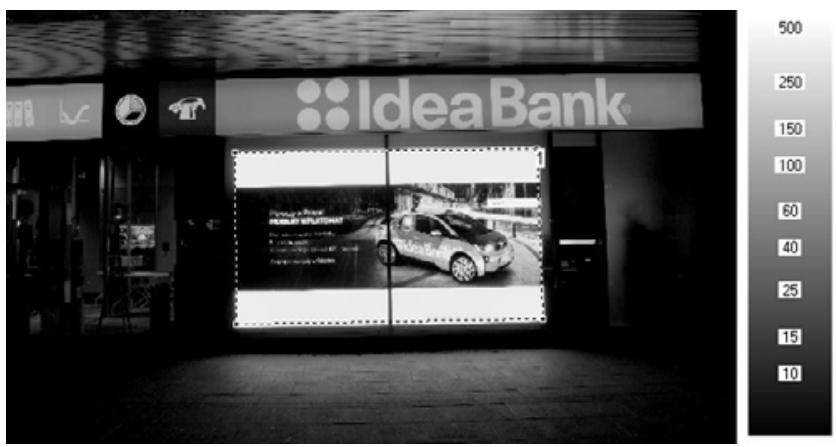

Fig. 6. The search for value $\operatorname{Lmax}\left[\mathrm{cd} / \mathrm{m}^{2}\right]$ using the meter matrix (318750 points - reference value).

Tab. 1. Investigating the maximum of luminance as a function of the size of the measuring field.

\begin{tabular}{|c|c|c|c|l|}
\hline No. & $\begin{array}{c}\text { Maximum } \\
\text { luminance } \\
\text { Lmax [cd/m2] }\end{array}$ & $\begin{array}{c}\text { Measurement } \\
\text { error [\%] }\end{array}$ & $\begin{array}{c}\text { Number of } \\
\text { picture [-] }\end{array}$ & \multicolumn{1}{c|}{ Comments } \\
\hline 1 & 132.1 & 69.2 & 6 & $\begin{array}{l}1 \text { measurement field } \\
126,000 \text { pix }\end{array}$ \\
\hline 2 & 286.2 & 33.3 & 5 & 15 fields (5x3) \\
\hline 3 & 383.5 & 10.62 & - & 325 fields (25x13) \\
\hline 4 & 414.8 & 3.34 & - & 1250 fields (50x25) \\
\hline 5 & 429.1 & - & 4 & $\begin{array}{l}1 \text { measurement field } \\
(750 x 425) 318,750 \text { pix }\end{array}$ \\
\hline
\end{tabular}


Analysing the results of the measurement of the luminance with the maximum greatest accuracy is achieved at the highest level of the discretization of the distribution surface. This follows from the fact that the gauge size of the luminance averages the maximum in the measurement. With a large field of measurement, there is a good chance that I'll be in the bright areas, but also heavily blacked out, which generally Fake it worth the read. When creating the procedures the technical capabilities of existing measures and technical conditions of measurement should be considered. The optimum division was at least 10 boxes horizontally and 10 vertically. Depending on the class of the meter (the size of the angular measurement field) it was necessary to adjust the distance measurement to obtain a box at the right surface.

In addition, measurements of the luminance distribution were taken of the surface of the selected media supports from all four representative groups. A measure matrix was used, as it was the most accurate measuring tool. The results are shown in Table 2 and Fig. 7 (maximum value and average luminance of the maximum of four similar supports).

Tab. 2 Measurements of Lmax selected ads of four representative groups.

\begin{tabular}{|c|c|c|c|c|c|c|}
\hline Group & $\begin{array}{c}\text { Maximum } \\
\text { of } \\
\text { luminance } \\
L_{\text {max }} \\
{\left[\mathbf{c d} / \mathbf{m}^{2}\right]} \\
\end{array}$ & $\begin{array}{c}\text { Average of } \\
\text { luminance } \\
\mathbf{L}_{\text {maxśr }} \\
{\left[\mathbf{c d} / \mathbf{m}^{2}\right]}\end{array}$ & $\begin{array}{c}1 \\
\text { advertise- } \\
\text { ment } \\
\mathbf{L}_{\max } \\
{\left[\mathrm{cd} / \mathbf{m}^{2}\right]} \\
\end{array}$ & $\begin{array}{c}2 \\
\text { advertise- } \\
\text { ment } \\
\mathrm{L}_{\max } \\
{\left[\mathrm{cd} / \mathbf{m}^{2}\right]} \\
\end{array}$ & $\begin{array}{c}3 \\
\text { advertise- } \\
\text { ment } \\
\mathbf{L}_{\max } \\
{\left[\mathbf{c d} / \mathbf{m}^{2}\right]} \\
\end{array}$ & $\begin{array}{c}4 \\
\text { advertise- } \\
\text { ment } \\
L_{\max } \\
{\left[\mathrm{cd} / \mathrm{m}^{2}\right]} \\
\end{array}$ \\
\hline A & 1087 & 1024 & 987 & 1005 & 1087 & 1018 \\
\hline B & 103 & 78 & 60 & 84 & 103 & 64 \\
\hline $\mathrm{C}$ & 278 & 257 & 245 & 234 & 278 & 271 \\
\hline $\mathrm{D}$ & 10 & 4 & 8 & 11 & 10 & 12 \\
\hline
\end{tabular}

The results obtained indicate that the highest luminance values are carriers of group A and $\mathrm{C}$, and they may cause the greatest driver distraction.

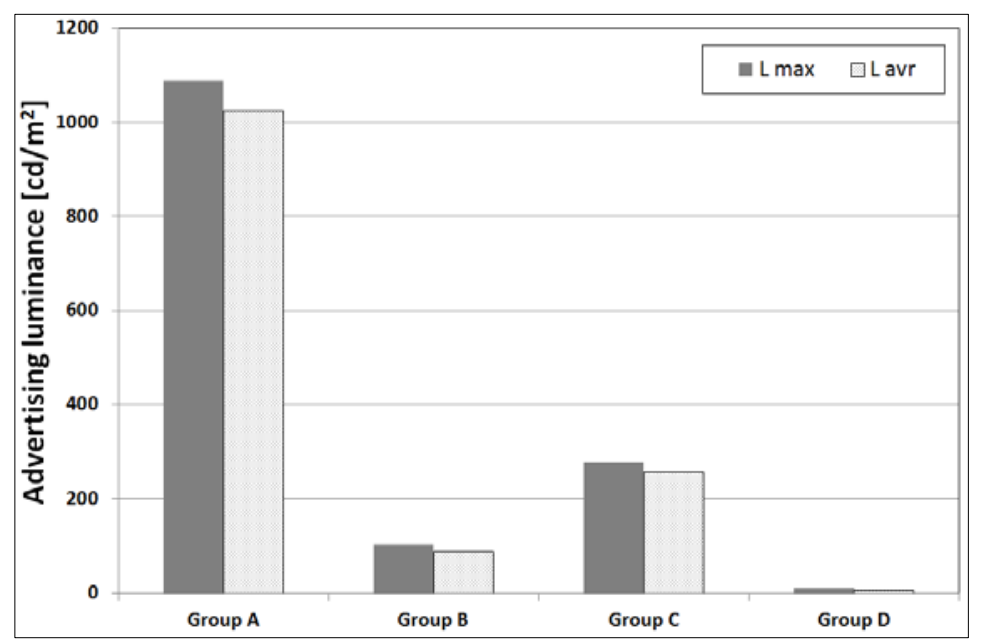

Fig. 7. Comparison of the maximum and average of luminance of representative ad groups. 


\section{Summary}

It is very important to undertake research towards establishing the acceptable levels of the performance of light beams emitted by ads. Each distraction of driver's attention visible on the road should have a very specific impact which should not significantly worsen the conditions of the driver's vision. In addition to specifying the limit value of the maximum luminance it is necessary to establish an unambiguous measurement procedure, so as to prevent undervaluation. The most important thing is to maintain the correct directions of measurement and the optimal size of the advertising media measuring field. The ad group A (LED, OLED) requires particular attention when creating the legal requirements and procedures. Further research will also be required to determine the impact of the reflective properties of the materials used on advertising media surfaces and the way the light beam affects the driver's visual competence which has a direct impact on road safety.

\section{Acknowledgements}

The issues presented in this article are the subject of the research and of analyses in the project carried out by the Department of Transport of the Warsaw Technical University entitled: Influence of Advertisements on the Security Level of Road Traffic, agreement number: DZP/RID-I-33/4/NCBR/ 2016 (Development of Road Innovation), financed by the National Centre of Research and Development and the General Management of National Roads and Motorways.

\section{References}

1. D. Beijer, Driver distraction due to roadside advertising (University of Toronto, Department of Mechanical and Industrial Engineering., 2002)

2. T. Dukic, C. Ahlstrom, C. Patten, C. Kettwich, K. Kircher, Effects of Electronic Billboards on Driver Distraction, Traffic Inj. Prev. 14 pp. 469-476 (2013). doi:10.1080/15389588.2012.731546

3. K. Domke, K. Wandachowicz, M. Zalesińska, S. Mroczkowska, P. Skrzypczak, Ocena zagrożeń występujących w ruchu drogowym powodowana przez wielkopowierzchniowe reklamy z diodami świecącymi, work no. 42-17-223-42050, grant no. RoM. III/3420-50/10 (Poznan, 2010)

4. Act of 21 March 1985 on Public Roads, OJ 2007 No. 19 Pos. 115 (Poland, 1985)

5. Guideline: Roadside Advertising Guide, Edition 1.2 (Departament of Transport and Main Roads, Australia, 2013)

6. S. Speirs, A. Winmill, T. Kazi, The Impact of Roadside Advertising on Driver Distraction: Final Report (WSP Development and Transportation, Basingstoke, 2008)

7. M. Zalesińska, K. Wandachowicz, The research of outdoor billbords with light emitting diode using luminance measuring camera, Pozn. Univ. Technol. Acad. Journals. Electr. Eng. 69 pp. 275-282 (2012)

8. Roadside advertising manual, Document No: AD-R-03 First Edition (Deparment of Transport United Arab Emirates, Abu Dhabi, 2013)

9. I. Lewin, Digital Billboard Recommendations and Comparisons to Conventional Billboards (Lighting Sciences Inc., Arizona, 2008)

10. Effects of roadside advertisements on road safety, Finnra Internal Reports 25/2004 (Helsinki, 2004) 
11. P.R. Boyce, Lighting for driving: roads, vehicles, signs, and signals (Taylor \& Francis Group, USA, 2009)

12. D. Beijer, A. Smiley, M. Eizenman, Observed Driver Glance Behavior at Roadside Advertising Signs, Transp. Res. Rec. J. Transp. Res. Board. 1899 pp. 96-103 (2004). doi:10.3141/1899-13

13. Act of 24 April 2015 amending certain acts on strengthening the tools for landscape protection, OJ 2015 Pos. 774 (Poland, 2015) 